Tropical Journal of Pharmaceutical Research December 2015; 14 (12): 2279-2286

ISSN: $1596-5996$ (print); 1596-9827 (electronic)

(c) Pharmacotherapy Group, Faculty of Pharmacy, University of Benin, Benin City, 300001 Nigeria.

All rights reserved.

Available online at http://www.tjpr.org

Original Research Article

http://dx.doi.org/10.4314/tjpr.v14i12.18

\title{
Therapeutic Effects of Water Extract of Arisaema Erubescens Tubers on Type II Collagen-induced Arthritis in Rats
}

\author{
Chong-bo Zhao, Xin-yi Li, Na Wu, Wei Peng, Yu-jie Liu and Chun-jie Wu* \\ College of Pharmacy, Chengdu University of Traditional Chinese Medicine, Chengdu, 611075, PR China
}

${ }^{*}$ For correspondence: Email: wucjcdtcm@163.com; Tel/Fax: +86-028-61801001

Received: 7 June 2015

Revised accepted: 4 November 2015

\begin{abstract}
Purpose: To investigate the anti-arthritic activity of the water extract of Rhizoma Arisaematis (WERA) using collagen II (CII)-induced arthritis (CIA) rat model.

Methods: CIA was induced in male Sprague-Dawley rat by intra-dermal injection of bovine collagen type II (C II) in Freund's complete adjuvant (cFA). The rats were treated daily for 21 consecutive days with WERA at doses of 100, 200, and $400 \mathrm{mg} / \mathrm{kg}$. Methotrexate (MTX) was used as positive control, and administered at a dose of $3 \mathrm{mg} / \mathrm{kg}$ intraperitoneally in two-weekly cycles for 3 weeks. Severity of arthritis was evaluated by arthritic scores, including paw swelling, arthritic score, body weight, thymus index and spleen index. The levels of IL-1 $\beta, I L-6, I L-10$ and TNF- $\alpha$ in serum were also measured.

Results: The results revealed that WERA significantly inhibited paw edema ( $p$-value $<0.01)$, decreased arthritis scores ( $p$-value $<0.01)$ and spleen index ( $p$-value $<0.05)$, and alleviated the weight loss of CIA rats. Furthermore, the pro-inflammatory cytokines of TNF- $\alpha(19.3 \%, 60.5 \%$ and $73.9 \%$, respectively), IL$1 \beta(7.9 \%, 41.1 \%$ and $52.7 \%$, respectively) and $I L-6(26.6 \%, 48.0 \%$ and $72.2 \%$, respectively) were remarkably attenuated in serum of all WERA-treated rats, however, IL-10 $(72.4 \%$ and $39.1 \%$, respectively) was markedly increased at doses of 200 and $400 \mathrm{mg} / \mathrm{kg}$ of WERA.

Conclusion: The results demonstrate that WERA exerts therapeutic effects in collagen--induced arthritis of rats by decreasing the levels of TNF- $\alpha, I L-1 \beta, I L-6$ and IL-10 in serum, and therefore may be an effective candidate drug for the treatment of human rheumatoid arthritis.
\end{abstract}

Keywords: Rhizoma Arisaematis, Rheumatoid arthritis, Inflammatory, Cytokines, Freund's complete adjuvant

Tropical Journal of Pharmaceutical Research is indexed by Science Citation Index (SciSearch), Scopus, International Pharmaceutical Abstract, Chemical Abstracts, Embase, Index Copernicus, EBSCO, African Index Medicus, JournalSeek, Journal Citation Reports/Science Edition, Directory of Open Access Journals (DOAJ), African Journal Online, Bioline International, Open-J-Gate and Pharmacy Abstracts

\section{INTRODUCTION}

Rheumatoid arthritis (RA) is an autoimmune disease characterized by synovial inflammation and hyperplasia, cartilage and bone destruction, chronic joint destruction with bone erosion in the extremities (especially the fingers) [1]. In addition, RA may also affect multiple organs and tissues, including the heart, lung, and nervous system. It's reported that RA occurs throughout the world with an average morbidity of $1 \%$ and its prevalence is three times more in females than in males [2]. It can rapidly progress into multi-system inflammation with irreversible joint damage, and causing premature mortality, disability and compromised quality of life in the industrialized and developing world [3,4].

Currently, the major RA medications used in clinical mainly include these categories: disease 
modifying anti-rheumatic drugs (DEMARDs), non-steroidal anti-inflammatory drugs (NSAIDs), steroid hormone and biologics (TNF- $\alpha$ antibody and the decoy TNF- $\alpha$ receptor,) [5]. Long-term use of these drugs easily leads to immune system weakness, bone marrow suppression, liver and kidney impairment, gastrointestinal discomfort and cartilage degeneration [6]. Thus, more effective drugs with low toxicity are needed. In recent years, increasing investigations reported that traditional Chinese medicines (TCMs) has provided effective avenues for discovering new drugs $[7,8]$. In addition, most RA patients are likely to use plant-derived agents for treating $R A[9,10]$. It might be a promising strategy to find new RA drugs from commonly used TCMs.

Rhizoma Arisaematis (RAM), the tubers of Arisaema erubescens (Wall.) Schott, has been used for more than two thousand years. As a folk remedy in China, RAM is mainly used to treat rheumatism, swelling, inflammation and convulsions. In addition, RAM is mainly used as a key component in formulations containing other medicines, such as Lijie Capsule, Fufang Nanxing Zhitong Gao and Aizheng Zhentong Powder [11-14]. Previous investigations indicate that the active components of RA include alkaloids, flavone, guanosine, polysaccharide, $\gamma^{-}$ aminobutyric acid, dipeptides and $\beta$-sitosterol, [15-18].

The present study was aimed to investigate the anti-arthritic effect of the water extract of Rhizoma Arisaematis (WERA) and explore its potential mechanisms.

\section{EXPERIMENTAL}

\section{Reagents and apparatus}

Bovine collagen type II (CII) and Complete Freund's Adjuvant (CFA) were purchased from Sigma (Sigma Chemical Co., USA) Methotrexate (MTX) was purchased from Shanghai Sine Pharmaceutical Co., Ltd. (Shanghai, China). TNF- $\alpha$, IL-1 $\beta$, IL- 6 and IL-10 ELISA kits were purchased from the R\&D system (R\&D Systems, USA). All the other chemicals and biochemicals used were of the highest grade available.

In the present study, the following instruments were used: Agilent 1260 Series High Performance Liquid Chromatography-Diode Array Detector (HPLC-DAD) (Agilent, USA), Plethysmometer PV-200 (ChengDu Technology \& Market Co., Ltd, Chengdu, China), FLx 800 Fluorescence Microplate Reader (BioTek,USA).
Water extraction of Rhizoma risaematis (WERA) Rhizoma Arisaematis (RAM) was purchased from Jiangyou Herbal Medicinal Materials Market in Sichuan Province, and identified by Prof. C.J. $\mathrm{Wu}$, Chengdu University of Traditional Chinese Medicine (CDUTCM) (Chengdu, China). A voucher specimen was deposited in College of Pharmacy, CDUTCM. Sliced dried tubers of Rhizoma Arisaematis were extracted two times (each extraction was last $2 \mathrm{~h}$ ) with hot water. The extract batches were then combined and centrifuged at $5000 \mathrm{rpm}$ for $20 \mathrm{~min}$ to remove starch. The supernatant was dried in a rotary evaporator to yield the dry extract.

\section{HPLC analysis of WERA}

The HPLC separation was performed on the Agilent 1260 HPLC system (Agilent Technologies) with a $\mathrm{C} 18$ chromatographic column ( $250 \mathrm{~mm} \times 4.6 \mathrm{~mm}$, i.d. $5 \mu \mathrm{m})$, equipped with a quaternary pump, and an automatic thermostatic column compartment. Separation was performed using gradient elution $\left[\mathrm{H}_{2} \mathrm{O}(\mathrm{A})\right.$ / methanol (B)] gradient at a flow rate of 0.8 $\mathrm{mL} / \mathrm{min}$. Samples were analyzed by using a gradient program as follows: run was commenced with $5 \% \mathrm{~B}$, linear gradient to $10 \%$ $B$ within 6 min, followed by linear gradient to 20 $\% \mathrm{~B}$ in $30 \mathrm{~min}$ until to $50 \mathrm{~min}$, and finally linear gradient to $30 \%$ B in 60 min.. The sample injection volume was $10 \mu \mathrm{L}$, the detection wavelength was set at $260 \mathrm{~nm}$, and the column temperature was set at $30^{\circ} \mathrm{C}$.

\section{Animals and grouping}

Male SD rats (weighing $160-180 \mathrm{~g}$ ) and $\mathrm{KM}$ mice (weighing $18-22 \mathrm{~g}$ ) were purchased from Chengdu Da-Shuo Lab Animal, LTD (Chengdu, China). They were kept in an environment with controlled temperature $\left(24-26{ }^{\circ} \mathrm{C}\right)$ and photoperiod (12:12 h) light-dark cycle. Animals were given standard commercial rat chow and water. Rats were acclimatized for 1 week before experiments and then randomly assigned to 6 groups: the normal group, the RA group, MTX group (3 $\mathrm{mg} / \mathrm{kg}$, twice/week), WERA low-dose group (100 mg/kg/d), WERA middle-dose group (100 mg/kg/d) and WERA high-dose group (400 $\mathrm{mg} / \mathrm{kg} / \mathrm{d}$ ), and each group consisted 10 animals. Animal experiments were conducted in accordance with current ethical regulations for animal care and use at Chengdu University of Traditional Chinese Medicine.

\section{Acute toxicity of WERA}

An acute toxicity study of the WERA was carried out using OECD guidelines [19]. The WERA was 
suspended in water with $0.5 \% \mathrm{w} / \mathrm{v}$ sodium carboxyl methyl cellulose (Na-CMC) in the doses of $5 \mathrm{mg} / \mathrm{kg}, 50 \mathrm{mg} / \mathrm{kg}, 500 \mathrm{mg} / \mathrm{kg}, 2 \mathrm{~g} / \mathrm{kg}, 5 \mathrm{~g} / \mathrm{kg}$ and $10 \mathrm{~g} / \mathrm{kg}$ body weight which were orally administered to the mice. The mortality rates of the mice were observed and recorded within 24 h.

\section{Collagen-induced arthritis (CIA)}

CIA model was established according to the methods described previously [20]. Collagen type II $(2 \mathrm{mg} / \mathrm{mL}$ in $0.05 \mathrm{M}$ acetic acid) was emulsified with an equal volume of complete Freund's adjuvant and a final concentration was $1 \mathrm{mg} / \mathrm{mL}$. Rats were injected subcutaneously at the tail root, hind-paw and three places at back (dorsonuchal, located towards the tail about twothirds and one-thirds of the way down its back) with the collagen emulsion ( $0.5 \mathrm{mg}$ per rat). After one week, a booster injection of the collagen emulsion ( $0.5 \mathrm{mg}$ per rat) was given at the same places. From 1 to 21 day after the first injected, the WERA group and MTX group were treated with WERA and MTX orally, the normal group and RA group were given an equal volume of the CMC-Na at the same time.

\section{Evaluation of the arthritic score}

Arthritis severity of the rats were assessed using the method described previously [21,22]. Paws were examined and graded for severity and loci of erythema, swelling and induration using a 5point scale: $0=$ no signs of disease, $1=$ signs involving the ankle/wrist, $2=$ signs involving the ankle plus tarsal of the hind paw and/or wrist plus carpals of the forepaw, $3=$ signs extending to the metatarsals or metacarpals, and $4=$ severe disease involving the entire hind or fore paw. The maximum arthritic score per rat was set at 16 (4 points $\times 4$ paws).

\section{Determination of index of thymus and spleen}

Treatment of 21 days, the rats were sacrificed under anesthesia (pentobarbital sodium, 40 $\mathrm{mg} / \mathrm{kg}$, i.p.). The thymus and spleen were then promptly removed and weighed. The index of thymus and spleen were expressed as the ratio, was divided body weight by thymus and spleen wet weight $(\mathrm{mg} / \mathrm{g})$, respectively [23].

\section{Determination of pro-inflammatory cytokines in serum}

Rat blood sample was obtained and allowed to clot for $1 \mathrm{~h}$ at room temperature. Subsequently, serum was recovered and frozen at $-20^{\circ} \mathrm{C}$ prior to analysis [24]. The contents of TNF- $\alpha$, IL-1 $1 \beta$, IL-
6 and IL-10 in serum were determined by commercial ELISA kits according to the manufacturer's protocol.

\section{Statistical analysis}

Data were presented as Mean \pm SD, and analyzed using SPSS 13.0 statistical software (SPSS Inc., Chicago, IL, USA). Differences between experimental groups were tested using one-way ANOVA, and $p<0.05$ was considered statistically significant.

\section{RESULTS}

\section{HPLC profile of WERA}

In the results of our investigation, three major constituents in the HPLC fingerprint of WERA were identified and recognized as inosine (retention time: $17.237 \mathrm{~min}$ ), guanosine (retention time: $19.108 \mathrm{~min}$ ) and adenosine (retention time: $37.762 \mathrm{~min}$ ) and computed the content was $0.008,0.051$, and $0.042 \mathrm{mg} / \mathrm{g}$, respectively (Fig 1).

\section{Acute toxicity of WERA}

According to advance with the OECD guidelines, the test animals were observed individually. In our toxicity study, neither death nor any abnormal neuro behaviors were observed during our test period, indicating that it is safe for WERA administration within the dose of $10 \mathrm{~g} / \mathrm{kg}$.

Effect of WERA on paw swelling, arthritis score and weight growth

No redness or joint swelling was observed in normal group (Figure 2 and $3 \mathrm{~A}$ ). The rats injected collagen exhibited peripheral paw edema in the first $24 \mathrm{~h}$. With 21 days treatment, the paw edema in WERA and MTX treated animals were almost disappeared In our results, WERA treatment significantly reduced the paw edema ( $p$-value $<0.05$ ) compared with rats in RA group during 10 to 21 days after immunization (Figures 2, 3B, D, E and F). MTX (3 mg/kg) also showed significant $(p<0.05)$ inhibitory effect on the paw edema (Figures 2 and $3 C$ ).

WERA at both 200 and $400 \mathrm{mg} / \mathrm{kg}$ doses significantly decrease arthritic scores of rats compared with the RA model group from the 13th day. WERA at $100 \mathrm{mg} / \mathrm{kg}$ dose decreased arthritic scores from day 13 to 18 , however it did not show significant difference with RA model group on day 21 . 



Figure 1: HPLC analysis of the water extract of Rhizoma Arisaematis (WERA). Peaks were detected at $260 \mathrm{~nm}$, and $1-3$ represented inosine, guanosine, and adenosine, respectively

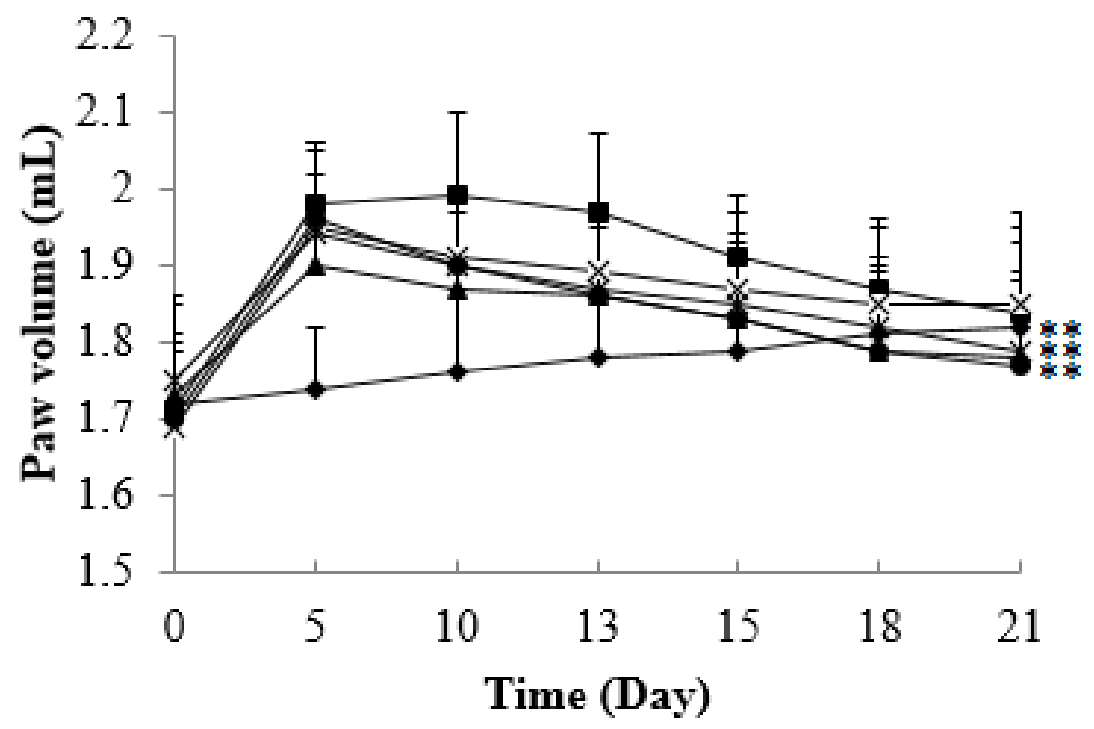

Figure 2: Effect of WERA on paw edema of RA rats. Key: $\bullet=$ Normal; $\boldsymbol{\square}=\mathrm{RA} ; \boldsymbol{\Delta}=\mathrm{MTX} ; \times=100 \mathrm{mg} / \mathrm{kg}, *=$ $200 \mathrm{mg} / \mathrm{kg}, \bullet=400 \mathrm{mg} / \mathrm{kg}$. Data are expressed as mean $\pm \mathrm{SD}(\mathrm{n}=10) ;{ }^{*} p<0.05,{ }^{* \star} p<0.01$, compared to RA control group 


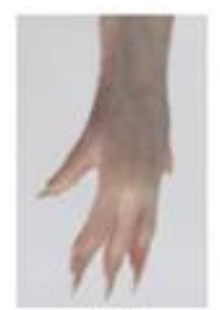

(A)

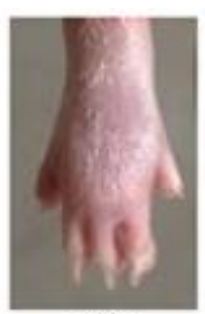

(B)

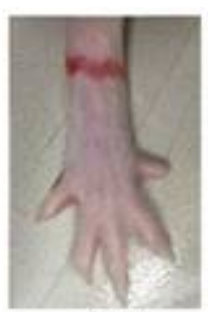

(C)

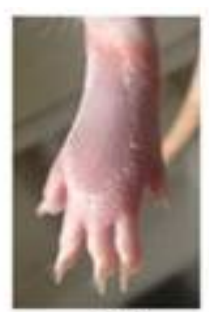

(D)

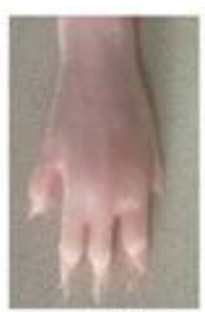

(E)

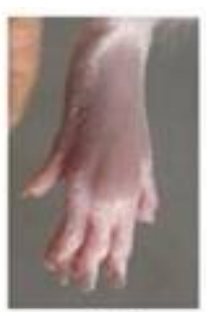

(F)

Figure 3: Representative paws of rats photographed on day 21. A-F represent the rats in normal group, RA model group, WERA at $100 \mathrm{mg} / \mathrm{kg}, 200 \mathrm{mg} / \mathrm{kg}, 400 \mathrm{mg} / \mathrm{kg}$, and MTX groups, respectively

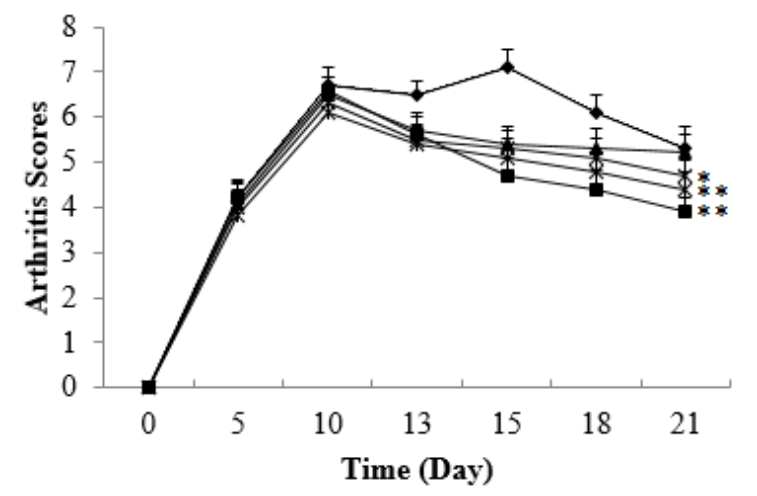

Figure 4: Effect of WERA on arthritic scores of RA rats. Note: $\bullet=\mathrm{RA} ; \boldsymbol{\square}=\mathrm{MTX} ; \boldsymbol{\Delta}=100 \mathrm{mg} / \mathrm{kg} ; \times=$ $200 \mathrm{mg} / \mathrm{kg} ; *=400 \mathrm{mg} / \mathrm{kg}$. Data are expressed as mean \pm SD $(\mathrm{n}=10) ;{ }^{*} p<0.05,{ }^{* \star} p<0.01$, compared to the RA control group

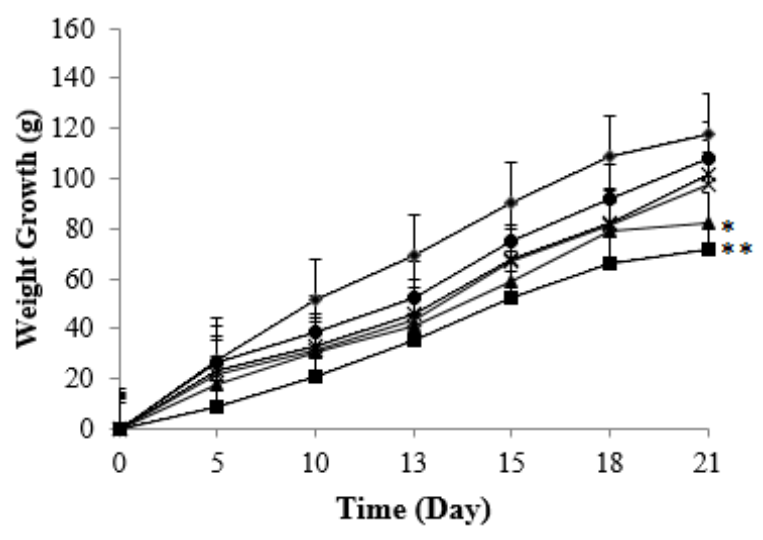

Figure 5: Effect of WERA on weight of RA rats. Note: $\checkmark=$ Normal; $\boldsymbol{\square}=\mathrm{RA} ; \boldsymbol{\Delta}=\mathrm{MTX} ; \times=100 \mathrm{mg} / \mathrm{kg} ; *=$ $200 \mathrm{mg} / \mathrm{kg} ; 0=400 \mathrm{mg} / \mathrm{kg}$; Data are expressed as mean $\pm \mathrm{SD}(\mathrm{n}=10) ;{ }^{*} p<0.05,{ }^{* *} p<0.01$, compared to RA control group

The similar efficacy of MTX (3 mg/kg) was also observed from day 13 to 21 (Fig 4).

RA rats showed marked weight loss compared with normal group on 5 th day ( $p$-value $<0.05$ ). During the next two weeks, the results showed the weight loss of RA rats were reversed by administration of WERA at 200, 400 and 100 $\mathrm{mg} / \mathrm{kg}$ (Figure 5). Although the weight gain in WERA-treated rats was lower than it had been initially, it was still much higher than that of MTX group rats. When compared with the normal group, animals treated with WERA did not show significant weight loss during the experiment.

\section{Effect of WERA on the index of thymus and spleen}

As shown in Fig. 6, both thymus index and spleen index in RA group were markedly increased compared with the normal group. The indices of spleen of the WERA treated animals were significantly decreased, and this situation can be reversed by both MTX (3 $\mathrm{mg} / \mathrm{kg})$ and WERA $(100,200$ and $400 \mathrm{mg} / \mathrm{kg})$. In addition, MTX (3 mg/kg) and WERA (400 mg/kg) also decreased thymus index.

\section{Effect of WERA on TNF- $\alpha$, IL-1 $\beta$, IL- 6 and IL- 10 in serum of RA rats}

As can be seen in Figure 7, significant increases of TNF- $\alpha(19.3,60.5$ and $73.9 \%$, respectively), IL-1 $\beta(7.9,41.1$ and $52.7 \%$, respectively) and IL6 (26.6, 48.0 and $72.2 \%$, respectively) in RA rats can be observed in serum of all WERA-treated rats, whereas the IL-10 (72.4 and $39.1 \%$, respectively) declined at doses of 200 and 400 $\mathrm{mg} / \mathrm{kg}$ of WERA compared with control rats. Both MTX (3 mg/kg) and WERA (200 and $400 \mathrm{mg} / \mathrm{kg}$ ) showed potent inhibitory effect on the production of TNF- $\alpha, \mathrm{IL}-1 \beta$ and IL-6 $(p<0.01)$, and WERA at the dose of $100 \mathrm{mg} / \mathrm{kg}$ showed inhibitory effects on TNF- $\alpha$ and IL-6 ( $p$-value < 0.05). Furthermore, WERA (200 and $400 \mathrm{mg} / \mathrm{kg}$ ) and MTX (3 mg/kg) markedly increased the IL-10 level in serum of RA rats ( $p$-value $<0.01)$.

\section{DISCUSSION}

In the present study, we have confirmed for the first time that WERA attenuate joint swelling of RA rats induced by type II collagen, and WERA 


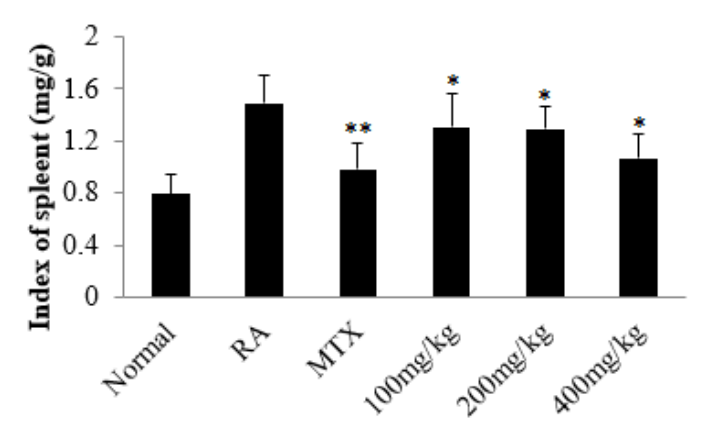

Treatment



Treatment

Figure 6: Effect of WERA on the indexs of thymus and spleen. Data are expressed as mean $\pm \operatorname{SD}(n=10) ;{ }^{*} p<$ $0.05,{ }^{* *} p<0.01$, compared to control group

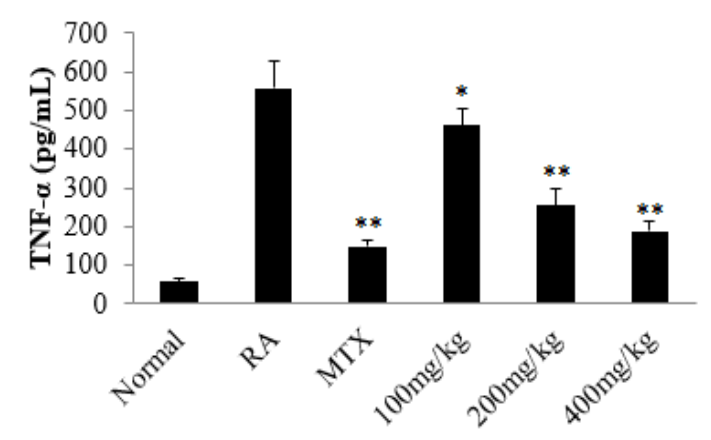

Treatment

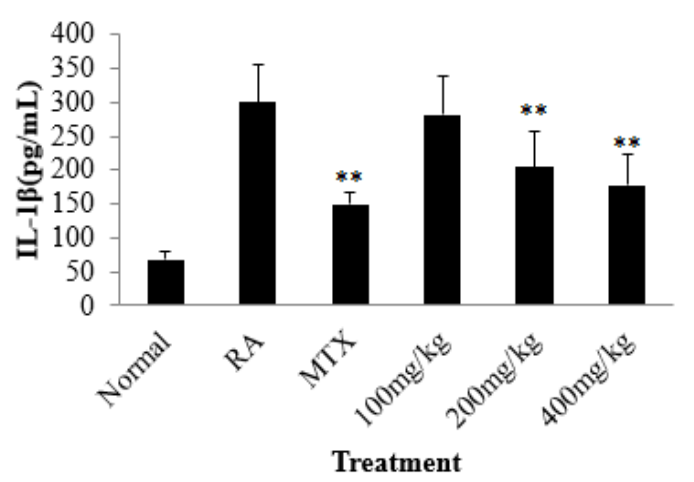



Treatment

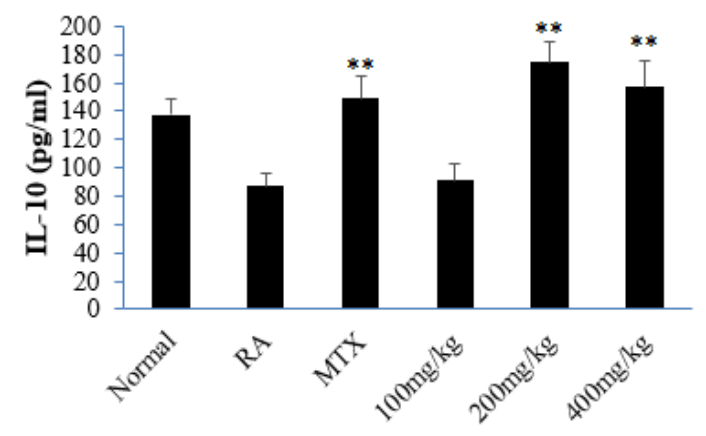

Treatment

Figure 7: Effects of WERA on TNF- $\alpha, \mathrm{IL}-1 \beta, \mathrm{IL}-6$ and IL-10 in serum of RA rats. Data are expressed as mean \pm SD $(\mathrm{n}=10) ;{ }^{*} p<0.05,{ }^{* *} p<0.01$, compared to control

can decrease the serum levels of some proinflammatory cytokines including TNF- $\alpha$, IL-1 $\beta$ and IL-6.

Collagen-induced arthritis in experimental animal model for RA in which the symptoms similar to human RA from genetic linkage to pathology and clinic manifestations. Thus, collagen-induced arthritis model is widely used to explore the pathogenesis and therapy principle of RA [26]. Therefore, arthritis model of rats induced by collagen was selected in our present investigation to study the anti-arthritic activity of WERA in vivo. That elimination of clinical symptoms of patients is a crucial index for evaluating the therapeutic effects of RA treatment [27]. Arthritic scores and paw swelling have usually been used for measurement of the anti-arthritic activity. Our study showed that orally treated WERA significantly relieved joint swelling and redness at the dose of 100, 200 and 400 $\mathrm{mg} / \mathrm{kg}$. Treatment with WERA can decreased the swelling paw volume and arthritic scores. In addition, WERA can also suppress the weight loss in Cll-induced RA rats.

It has been reported that pro-inflammatory cytokines such as TNF- $\alpha, \mathrm{IL}-1 \beta$, and IL- 6 are documented as being critically important in development of RA $[28,29]$. TNF- $\alpha$ has been 
considered to be on top of a cytokine cascade, which can increase the releases of IL-6 and IL$1 \beta$, and stimulate cartilage matrix degradation. In addition, IL-1 $\beta$ and IL- 6 have also been reported to contribute to the development of arthritis $[30,31]$. IL-10 played a vitally important role in protecting the integrality of joint tissues; inhibit cytokine production, and inhibit IL-18 mRNA expression in pathological process of RA $[32,33]$. In this study, WERA significantly decreased the serum levels of TNF- $\alpha$, IL- $1 \beta$ and IL- 6 , whereas the level of $\mathrm{IL}-10$ was markedly increased at doses of 200 and $400 \mathrm{mg} / \mathrm{kg}$. Thus, the mechanism for the therapeutic effect of WERA on RA may be involved in both down-regulating the level of TNF- $\alpha, \quad \mathrm{IL}-1 \beta$ and IL- 6 and upregulating the expression of IL-10.

Thymus and spleen are the two major organs of the body immune organs, and the relative weights of thymus and spleen are usually used to evaluate the drugs immunoregulatory activity. After administration of WERA, the RA rats exhibited a marked reduction of index of spleen and thymus $(400 \mathrm{mg} / \mathrm{kg})$. This result indicated that WERA might affect immune function on RA rats.

By HPLC fingerprint analysis, we found that the main components of WERA were nucleosides. Nucleosides were previously found to be immunostimulatory activity agents [34], therefore, according to our results, we can deduct that the nucleosides in WERA, may be responsible for the observed anti-arthritic activity.

\section{CONCLUSION}

The results of the present study suggest that the water extract of Rhizoma arisaematis is therapeutically effective in Cll-induced arthritis in rats. Its effects may be attributed to its ability to decrease spleen index, down-regulate TNF- $\alpha$, IL$1 \beta$ and IL- 6 levels, and up-regulate concentration of IL-10 levels, suggesting that the plant can potentially be developed for the treatment or prevention of RA.

\section{REFERENCES}

1. Mclnnes IB, Schett G. The Pathogenesis of Rheumatoid Arthritis. New Engl J Med 2011; 365: 2205-2219.

2. Firestein GS. Evolving concepts of rheumatoid arthritis. Nature 2003; 423: 356-361.

3. Panayi GS. B cells: a fundamental role in the pathogenesis of rheumatoid arthritis? Rheumatology (Oxford) 2005; 44: 113-117.
4. Smolen JS, Aletaha D. Developments in the clinical understanding of rheumatoid arthritis. Arthritis Res Ther 2009; 11: 204-213.

5. Kim KR, Chung TY, Shin H, Son SH, Park KK, Choi JH, Chung WY. Red ginseng saponin extract attenuates murine collagen-induced arthritis by reducing proinflammatory responses and matrix metalloproteinase-3 expression. Biol Pharm Bull 2010; 33: 604-610.

6. Kremers HM, Nicola P, Crowson CS, O'Fallon WM, Gabriel SE. Therapeutic strategies in rheumatoid arthritis over a 40-year period. J Rheumatol 2004; 31 : 2366-2373.

7. Schmidt BM, Ribnicky DM, Lipsky PE, Raskin I. Revisiting the ancient concept of botanical therapeutics. Nat. Chem. Biol 2007; 3: 360-366.

8. Peng $W, W u$ JG, Jiang YB, Liu YJ, Sun T, Wu N, Wu CJ. Antitumor activity of 4-O-(2"-O-acetyl-6"-O-pcoumaroyl- $\beta$-D-glucopyranosyl)-p-coumaric acid against lung cancers via mitochondrial-mediated apoptosis. Chem Biol Interact 2015: 233: 8-13.

9. Wang M, Li K, Nie Y, Wei $Y$, Li X. Antirheumatoid arthritis activities and chemical compositions of phenolic compounds-rich fraction from Urtica atrichocaulis, an endemic plant to China. Evid Based Complement Alternat Med 2012; 2012 (Article ID 818230):1-10.

10. Rao JK, Mihaliak K, Kroenke K, Bradley J, Tierney WM, Weinberger $M$. Use of complement arytherapies for arthritis among patients of rheumatologists. Ann Intern Med 1999; 131: 409-416.

11. LIU J, SUN Y. How does Chinese medicine target cytokine imbalance in Rheumatoid Arthritis? Chin J Integr Med 2013; 19: 874-880.

12. Wang XZ, Cao YL, Pang J, Du J, Guo CQ, Liu T, Wei SP, Zheng YX, Chen RM, Zhan HS. Traditional Chinese herbal patch for short-term management of knee osteoarthritis: A randomized, double-blind, placebocontrolled trial. Evidence-Based Complementary and Alternative Medicine 2012; 2012: 171706.

13. Shan YU, Ling XU, Wei PK, Qin ZF, Li J, Peng HD. Study on analgesic effect of traditional Chinese medicine. Chin J Integr Med 2008; 14: 151-156.

14. Chen G, Xu J, Miao X, Huan Y, Liu X, Ju Y, Han XS. Characterization and antitumor activities of the watersoluble polysaccharide from Rhizoma Arisaematis. Carbohydr Polym 2012; 90: 67- 72.

15. Ahn CB, Shin TS, Seo HK, Je JY. Phenolic composition and antioxidant effect of aqueous extract of Arisaema cum Bile, the Oriental Herb Medicine, in human fibroblast cells. Immunopharmacology and Immunotoxicology 2012; 34: 1-6.

16. Du SS, Lei N, Xu YC, Wei LX. Study on flvaonids of Arisaema erubescens. Chin Pharm J. 2005; 40: 1457-1459.

17. Ducki SW, Hadfield JA, Lawrence NJ, Zhang, X, McGown AT. Isolation of Paeonol from Arisaema erubescens. Planta Med 1995; 61: 586-587. 
18. Prakash S, Sinha GK. Chemical examination of Arisaema curvatum Kunth (Part I). Nat Appl Sci Bull 1974; 26 : 25-27.

19. OECD, Guidance Document on Acute Oral Toxicity Testing, Series on Testing and Assessment No. 24, Organization for Economic Cooperation and Development, OECD Environment, Health and Safety Publications, Paris. 2001 [cited 2015 Mar 26]. Available from: http:/ www.oecd.org/ehs

20. Zhang $Y, X u W$, Li H, Zhang $X, X i a Y$, Chu K, Chen $L$. Therapeutic effects of total alkaloids of tripterygium wilfordii Hook $f$. on collagen-induced arthritis in rats. Journal of Ethnopharmacology 2013; 145: 699-705.

21. Suszko A, Obmin'ska-Mrukowicz B. Influence of polysaccharide fractions isolated from Caltha palustris $L$. on the cellular immune response in collagen-induced arthritis(CIA)in mice. A comparison with methotrexate. Journal of Ethnopharmacology 2013; 145: 109-117.

22. Zhu XJ, Zhang J, Huo RF, Lin JP, Zhou Z, Sun $Y$, Wu $P R$, Li HD, Zhai TH, Shen BH, Li NL. Evaluation of the efficacy and safety of different Tripterygium Preparations on collagen-induced arthritisinrats. Journal of Ethnopharmacology 2014; 158: 283-290.

23. Zhang LL, Wei W, Yan SX, Hu XY, Sun WY. Therapeutic effects of glucosides of Cheanomeles speciosa on collagen-induced arthritis in mice. Acta Pharmacologica Sinica 2004; 25: 1495-1501.

24. Anderson GD, Hauser SD, McGarity KL, Bremer ME, Isakson $P C$, Gregory SA. Selective inhibition of cyclooxygenase (COX)-2 reverses inflammation and expression of COX-2 and interleukin 6 in rat adjuvant arthritis. Journal of Clinical Investigation 1996; 97 : 2672-2679.

25. HUANG J, YI JH, LIU YH, HUANG ZF, CHEN Y, LIU YH. Determination of Eight Nucleosides in Rhizoma Arisaema, Rhizoma Pinellie and Rhizoma Typhonii.
Chinese Journal of Experimental Traditional Medical Formulae 2013; 19: 59-62.

26. Trentham $D E$, Townes AS, Kang AH. Autoimmunity to type II collagen an experimental model of arthritis. Journal of Experimental Medicine 1977; 146: 857868.

27. C`apit`anescu B, Simionescu C, Stepan A, Margaritescu C, Georgescu CV, Rosu A. CD20cy and CD45RO immunoexpression in early rheumatoid arthritis synovium. Romanian Journal of Morphology and Embryology 2010; 51: 49-54.

28. Jacques $C$, Gosset $M$, Berenbaum $F$, Gabay $C$. The role of IL-1 and IL-1Ra in joint inflammation and cartilage degradation. Vitamins and Hormones 2006; 74: 371403.

29. Sweeney SE, Firestein GS. Rheumatoid arthritis: regulation of synovial inflammation. The International Journal of Biochemistry and Cell Biology 2004; 36: 372-378.

30. Goldring MB. The role of the chondrocyte in osteoarthritis. Arthritis and Rheumatism 2000; 43: 1916-1926.

31. Smolen JS, Steiner G. Therapeutic strategies for rheumatoid arthritis. Nature Reviews. Drug discovery 2003; 2: 473-488.

32. Fiorentino DF, Zlotnik A, Vieira P, Mosmann TR, Howard M, Moore KW, O'Garra A. IL-10 acts on the antigenpresenting cell to inhibit cytokine production by Th1 cells. Journal of Immunology 1991; 146: 3444-3451.

33. Katsikis $P D$, Chu CQ, Brennan FM, Maini RN, Feldmann M. Immunoregulatory role of interleukin 10 in rheumatoid arthritis. Journal of Experimental Medicine 1994; 179: 1517-1527.

34. Lee J, Chuang TH, Redecke V, She L, Pitha PM, Carson $D A$, Raz E, Cottam HB. Molecular basis for the immunostimulatory activity of guanine nucleoside analogs: activation of Toll-like receptor 7. Proc Natl Acad Sci USA 2003; 100: 6646-6651. 